\title{
Brain Region-Specific Mechanisms for Acute Morphine- Induced Mitogen-Activated Protein Kinase Modulation and Distinct Patterns of Activation during Analgesic Tolerance and Locomotor Sensitization
}

\author{
Shoshana Eitan, ${ }^{1}$ Camron D. Bryant, ${ }^{1,2}$ Nazli Saliminejad, ${ }^{1}$ Yu C. Yang, ${ }^{1}$ Elroy Vojdani, ${ }^{1}$ Duane Keith Jr, ${ }^{1}$ \\ Roberto Polakiewicz, ${ }^{3}$ and Christopher J. Evans ${ }^{1}$ \\ ${ }^{1}$ Department of Psychiatry and Biobehavioral Sciences, University of California, Los Angeles, Neuropsychiatric Institute, and ${ }^{2}$ Interdepartmental Program \\ in Neuroscience, University of California, Los Angeles, Los Angeles, California 90024, and ${ }^{3}$ Cell Signaling Technology, Beverly, Massachusetts 01915
}

\begin{abstract}
Opioid-receptor activation in cell lines results in phosphorylation of p42/44 mitogen-activated protein kinase (MAPK), which contributes to agonist-induced desensitization of adenylate cyclase signaling. In this study, morphine-induced MAPK modulation was examined in the mouse brain using antibodies against phosphorylated MAPK. Thirty minutes after systemic morphine, MAPK modulation was observed in brain areas associated with analgesia and reward. Activation of MAPK was increased in the anterior cingulate (Acc), somatosensory and association cortices, and locus ceruleus (LC). In contrast, MAPK activation was decreased in the nucleus accumbens and central amygdala (CeA). Double-label confocal microscopy revealed that morphine-induced MAPK modulation occurred predominantly in cells not expressing $\mu$-opioid receptors, with the exception of the LC. Furthermore, the NMDA receptor antagonist 3,3-(2carboxypiperazine-4-yl)-propyl-1-phosphonate blocked morphine-induced MAPK modulation in several cortical areas including the Acc. We then examined morphine-induced MAPK modulation during expression of either analgesic tolerance or locomotor sensitization, which were differentiated by two repeated morphine regimens. Analgesic tolerance was accompanied by tolerance to morphine-induced MAPK modulation in all of the brain areas examined except the CeA. Locomotor sensitization resulted in sensitization to morphineinduced MAPK activation in the posterior basolateral amygdala. Additionally, a pronounced instatement of morphine-induced MAPK activation was observed in CA3 hippocampal processes. This instatement was observed during expression of tolerance; however, it was not significant during sensitization. In summary, these results provide distinct, region-specific mechanisms for morphine-induced MAPK modulation in the mouse brain and give insight into the brain circuitry involved in acute and adaptive opioid behaviors.
\end{abstract}

Key words: antinociception; reward; opioid; extracellular-regulated kinase (ERK)1/2; hot plate; opioid signaling; NMDA; $\mu$

\section{Introduction}

Opiates are the most effective and commonly used analgesics in treating moderate-to-severe pain. However, their use is compromised by analgesic tolerance and their high potential for abuse. In addition to tolerance, repeated opiate administration in rodents also results in locomotor sensitization, a model for drug craving and relapse (Robinson and Berridge, 1993).

Opioid receptors are G-protein-coupled receptors (GPCRs) that modulate many signaling pathways including several kinase cas-

Received March 28, 2003; revised July 11, 2003; accepted July 16, 2003.

This work was supported by National Institute on Drug Abuse (NIDA) Grant DA05010 and Human Frontiers Grant 01030586. Funding for S.E., C.D.B., Y.C.Y., and E.V. was provided in part by the Shirley and Stefan Hatos Neuroscience Research Foundation. C.D.B. is funded by NIDA Training Grant DA07272. We thank Andrew Bokarius, Sara Levitt, and Jo-Lawrence Bigcas for helping with the data analysis and videotape scoring of locomotor activity. Confocal microscopy was performed in the University of California, Los Angeles, Brain Research Institute, Carol Moss Spivak Cell Imaging Center, with advice from Dr. Matt Schibler.

Correspondence should be addressed to Dr. Christopher J. Evans, Department of Psychiatry and Biobehavioral Sciences, University of California, Los Angeles, Neuropsychiatric Institute, 760 Westwood Plaza, Los Angeles, CA 90024.E-mail: cevans@ucla.edu.

Copyright $\odot 2003$ Society for Neuroscience $\quad$ 0270-6474/03/238360-10\$15.00/0 cades such as those containing protein kinase $\mathrm{C}$ (PKC), CaM kinase II, p42/44 mitogen-activated protein kinase (MAPK), and Akt [also known as protein kinase B (PKB)] (for review, see Law et al., 2000; Williams et al., 2001). Stimulation of several GPCRs, including opioid receptors, leads to MAPK phosphorylation (activation) in vitro. MAPK can also be activated by ionotropic receptors including NMDA receptors (Gutkind, 2000). Phosphorylation of MAPK leads to signaling in the cytoplasm as well as modulation of gene expression after nuclear translocation [e.g., cAMP response elementbinding protein (CREB)] (Adams et al., 2000).

Several types of synaptic plasticity require MAPK activation, including NMDA receptor-dependent long-term potentiation (LTP) and depression in CA1 of the hippocampus (Sweatt, 2001; Thiels et al., 2002) and activity-dependent dendrite formation in sympathetic neurons (Vaillant et al., 2002). MAPK and NMDA receptors also contribute to behavioral plasticity including morphine-conditioned place preference and analgesic tolerance (Marek et al., 1991; Trujillo and Akil, 1991; Mazzucchelli et al., 2002). Furthermore, systemic morphine administration modulates hippocampal LTP (Mansouri et al., 1997, 1999; Harrison et 
al., 2002; Pu et al., 2002) and induces persistent changes in excitatory transmission in the ventral tegmental area (VTA) (Saal et al., 2003). Thus, localizing brain areas in which morphine modulates MAPK activation and determining the potential role of NMDA receptor activation in this process may identify areas of synaptic plasticity that contribute to opiate adaptive behaviors.

In cell lines, MAPK phosphorylation is critical for opioidreceptor desensitization (Polakiewicz et al., 1998a) and regulation of $\beta$-arrestin translocation to the membrane (Eisinger et al., 2002). With respect to in vivo function, an involvement of MAPK in opioid analgesia and sedation has also been proposed (Gutstein et al., 1997). However, in vivo studies of opioid modulation of MAPK are limited. In an early study, chronic, but not acute, morphine administration increased MAPK activity in the VTA (Berhow et al., 1996). Chronic morphine diminished phosphoMAPK staining in the cortex (layers II/III), median eminence, amygdala, and hypothalamic nuclei (Schulz and Hollt, 1998). Naloxone-precipitated withdrawal produced a dramatic increase in phospho-MAPK in areas involved in stress including the locus ceruleus (LC), solitary tract, and hypothalamus (Schulz and Hollt, 1998).

Here, we first examined the acute effect of morphine on MAPK activation in the brain under conditions in which animals were habituated to the stress of handling and the injection procedures. We then determined whether there was coexpression of phosphorylated MAPK with $\mu$-opioid receptors and whether morphine-induced MAPK activation required NMDA receptor activation. Finally, we examined the patterns of MAPK modulation after two repeated morphine administration protocols that result in either analgesic tolerance or locomotor sensitization at the time of assessment.

\section{Materials and Methods}

Animals and drugs. Male C57BL/6J mice (7-9 weeks of age; The Jackson Laboratory, Bar Harbor, ME) were used for all of the experiments and housed four per cage with food and water ad libitum. All of the procedures were conducted in accordance with the National Institutes of Health Guide for the Care and Use of Laboratory Animals and were approved by the Institutional Animal Care and Use Committee. Separate animal groups were used for behavioral analysis and immunohistochemistry. Morphine sulfate was obtained from National Institute on Drug Abuse (Bethesda, MD). 3,3-(2-Carboxypiperazine-4-yl)-propyl-1phosphonate (CPP) was purchased from Sigma (St. Louis, MO).

Acute morphine and CPP administration. For studies of acute morphine administration, mice $(n=5-12)$ were habituated to the injection procedure by injections twice daily for $6 \mathrm{~d}$ of saline (subcutaneous). On day 7 , mice were injected subcutaneously with saline, $10 \mathrm{mg} / \mathrm{kg}$ morphine, or $100 \mathrm{mg} / \mathrm{kg}$ morphine. For the CPP studies, mice $(n=4-8)$ were habituated by injections of saline intraperitoneally and subcutaneously once daily for $6 \mathrm{~d}$. On day 7, mice were injected intraperitoneally with saline or $30 \mathrm{mg} / \mathrm{kg}$ CPP followed by subcutaneous injection of saline or $10 \mathrm{mg} / \mathrm{kg}$ morphine. All of the drugs were injected in a volume of 10 $\mathrm{ml} / \mathrm{kg}$.

Administration protocols. We used two protocols of repeated morphine administration over $6 \mathrm{~d}$. The first protocol is termed "twice daily ascending doses" (TAD), in which mice were injected twice daily (A.M. and P.M.) for $6 \mathrm{~d}$ with ascending doses of morphine $(10-40 \mathrm{mg} / \mathrm{kg}$, s.c.) for a total of 12 injections. Specifically, on days 1 and 2, mice were injected with $10 \mathrm{mg} / \mathrm{kg}$. On days 3 and 4, mice were injected with $20 \mathrm{mg} / \mathrm{kg}$. On days 5 and 6 , mice were injected with $40 \mathrm{mg} / \mathrm{kg}$. In the second protocol, termed "every other day" (EOD), mice were injected every other day once per day in the A.M. over the course of $6 \mathrm{~d}$ with $20 \mathrm{mg} / \mathrm{kg}$ morphine (subcutaneous) for a total of three injections. Thus, on days 1, 3, and 5, mice were injected with morphine. Control mice for TAD and EOD protocols were injected with saline, using the same schedule as for morphine injections to control for injection stress and handling.
Nociceptive testing. Mice $(n=7-8)$ were transported to a separate procedure room in close proximity to the vivarium, habituated for $1 \mathrm{hr}$, and injected with saline or morphine according to TAD or EOD protocols. On day 7, mice were transported to the procedure room and habituated for $1 \mathrm{hr}$. They were then tested for baseline nociception and morphine analgesia with the $52.5^{\circ} \mathrm{C}$ hot-plate assay. In this assay, mice were placed inside a Plexiglas cylinder $(7.5 \mathrm{~cm}$ diameter $\times 13 \mathrm{~cm}$ height $)$ on top of a hot plate. The small size of the cylinder reduces the possibility that locomotor activity interferes with the application of the nociceptive stimulus. The nociceptive response was defined as the latency to lick or flick the hindpaw. In measuring analgesia, a cutoff latency of $60 \mathrm{sec}$ was used to minimize tissue damage. Thirty minutes after baseline measurements, mice were injected with $10 \mathrm{mg} / \mathrm{kg}$ morphine (subcutaneous) and tested for analgesia every $30 \mathrm{~min}$ for a total of $180 \mathrm{~min}$.

Locomotor sensitization. Locomotor activity was evaluated in the home cage using video monitoring. Mice $(n=6-8)$ were identified by striping their tails with a white marker. For video monitoring, the cage tops were removed and transparent Lexan tops, perforated with several holes, were taped $1.4 \mathrm{~cm}$ above the cages to provide adequate ventilation. The tops were divided into six squares $(\sim 9.5 \times 9.5 \mathrm{~cm})$ using 6.5 -mm-wide tape. Mice were habituated to video monitoring $2 \mathrm{~d}$ before injections. During experimentation, video monitoring was conducted every other day (days 1, 3, and 5) for $180 \mathrm{~min}$. After $90 \mathrm{~min}$ of habituation, mice were injected with either saline or morphine according to TAD or EOD protocols and monitored for an additional $90 \mathrm{~min}$. On day 7, mice were habituated for $90 \mathrm{~min}$, injected with $5 \mathrm{mg} / \mathrm{kg}$ morphine (subcutaneous), and monitored for an additional $90 \mathrm{~min}$.

In measuring locomotor activity, the number of crossovers per $15 \mathrm{~min}$ was recorded for each mouse. A crossover was defined as the placement of all four paws into one of six possible squares. The experimenters who recorded the locomotor activity were blind to the conditions.

Phospho-MAPK staining. Pentobarbital (100 mg/kg, i.p.) was injected 27 min after saline or morphine injection. Three minutes later, mice were perfused with $50 \mathrm{ml}$ of ice-cold PBS followed by $200 \mathrm{ml}$ of $4 \%$ paraformaldehyde. Brains were removed, postfixed overnight in $4 \%$ paraformaldehyde at $4^{\circ} \mathrm{C}$, cryoprotected in $30 \%$ sucrose at $4^{\circ} \mathrm{C}$ for $2 \mathrm{~d}$, and frozen embedded in Tissue-Tek optimal cutting temperature (OCT) compound (Sakura Finetek, Torrance, CA). Brains were then cryosectioned at 40 $\mu \mathrm{m}$ and stored in PBS containing $0.1 \%$ thimerosal at $4^{\circ} \mathrm{C}$. Immunohistochemistry was performed simultaneously on control and treated brain sections using the free-floating method. Briefly, sections were incubated overnight with antibodies against phospho-p42/44 MAPK (Cell Signaling Technology, Beverly, MA) diluted 1:300 at $4^{\circ} \mathrm{C}$. Sections were then washed and incubated with biotin-conjugated anti-rabbit antibodies followed by $\mathrm{ABC}$ enhancement (Vector Laboratories, Burlingame, CA), and staining was revealed using 3,3'-diaminobenzidine (DAB) tablets (Sigma).

After staining, digital pictures were taken using an Olympus Optical (Tokyo, Japan) BX60 microscope using a Spot digital camera (Diagnostic Instruments, Sterling Heights, MI) and stored using Adobe Photoshop (Adobe Systems, San Jose, CA). Particle analysis was performed in regions of interest using NIH Image 1.62 for either the total pixels stained per brain area and/or the average optical density of the stained pixels, depending on the region. For each mouse and brain area, 5-12 consecutive sections (depending on the size of the brain area) were analyzed and averaged. Results are presented from 5-12 mice per treatment group.

For double labeling, tissue was processed as it was for peroxidase labeling, and immunohistochemistry was performed using the freefloating method. Sections were incubated overnight with antibodies against phospho-p42/44 MAPK (Cell Signaling Technology) and antibodies against a previously characterized C-terminally directed rabbit anti- $\mu$-opioid receptor (Unterwald et al., 1998) diluted 1:300 at $4^{\circ} \mathrm{C}$. Sections were then washed and incubated with FITC-conjugated antirabbit (Jackson ImmunoResearch, West Grove, PA) diluted 1:100 and cyanine 3-conjugated anti-mouse (Jackson ImmunoResearch) diluted 1:600. Staining was visualized using a Leica (Nussloch, Germany) TCS SP MP inverted confocal microscope.

Data analysis. In analyzing morphine analgesia, hot-plate latencies after morphine administration were normalized to baseline latencies ac- 


\section{Saline}

A.
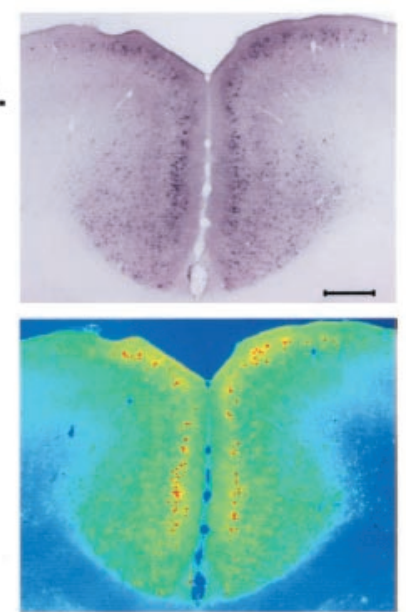

C.
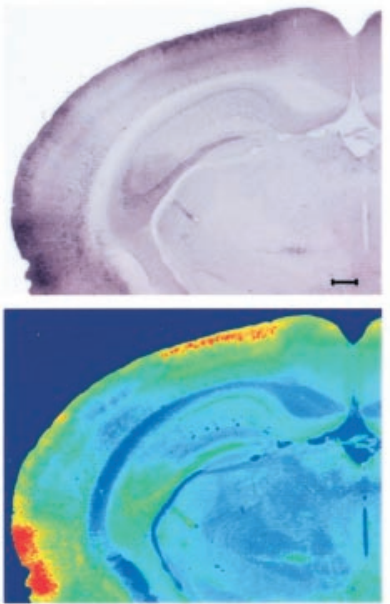

E.
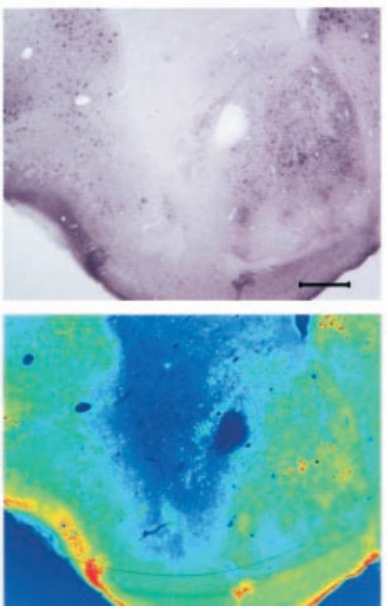

Morphine (10 mg/kg)
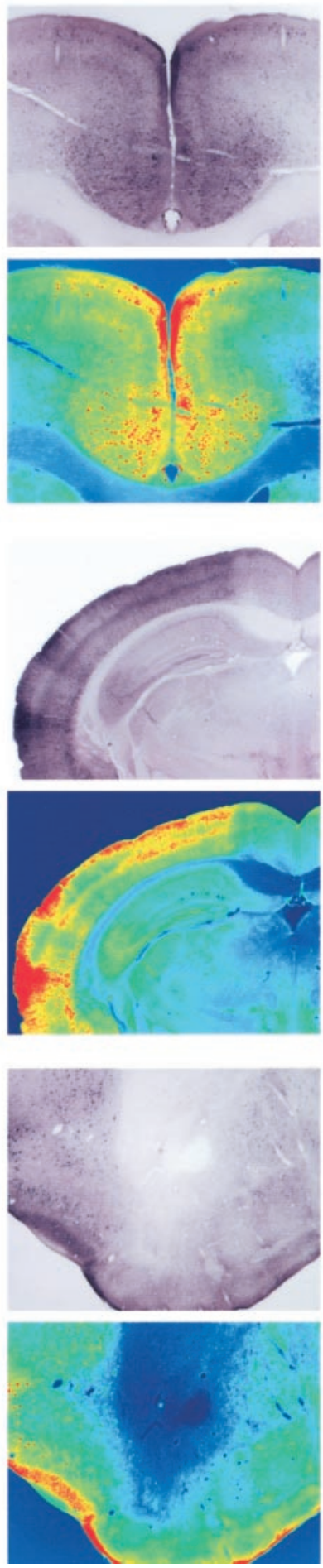

Saline

B.
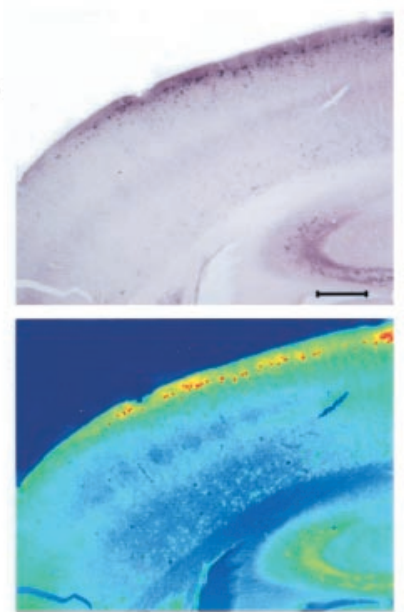

D.
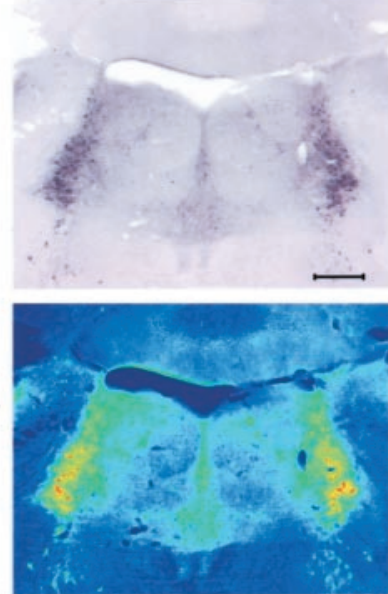

F.
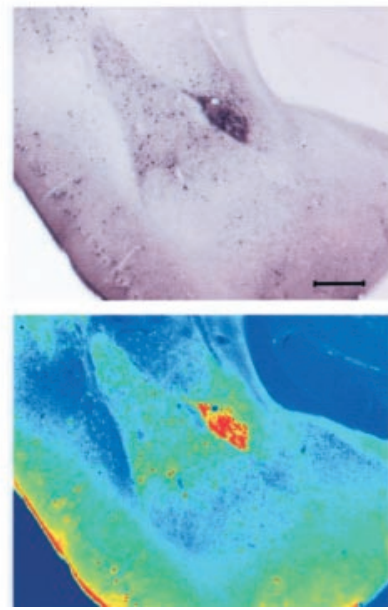

Morphine (10 mg/kg)
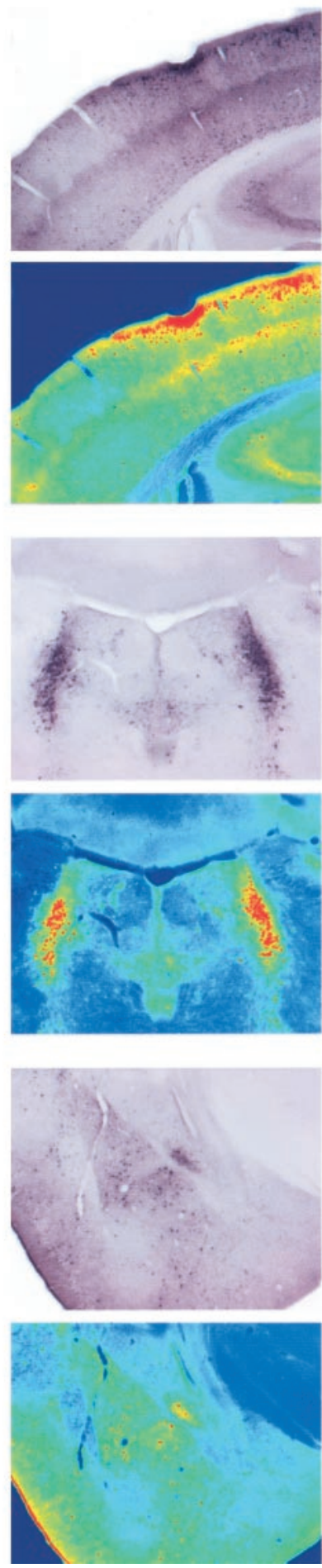

Figure 1. Acute morphine administration modulates MAPK activation in the brain. Mice were habituated to injections for $6 \mathrm{~d}$ and, on day 7 , were injected with either saline or $10 \mathrm{mg} / \mathrm{kg} \mathrm{morphine}$ (subcutaneous). Thirty minutes after injection, mice were perfused, and brains were processed for immunohistochemistry. A morphine-induced increase in MAPK activation was observed in the Acc $(A)$, somatosensory cortex $(B)$, association cortex $(C$, and the $L C(D)$. A decrease in MAPK activation was observed in the $\operatorname{NAC}(E)$ and $C$ eA $(F)$. For each panel, the top photographs are representative DAB-stained sections for each brain area, and the bottom photographs are pseudocolor presentations of these images. Scale bars, $300 \mu \mathrm{m}$.

cording to the percentage of maximum possible effect (\% MPE) using the following formula: $\% \mathrm{MPE}=$ (postmorphine latency - baseline laten$\mathrm{cy}) /($ cutoff latency - baseline latency) $\times 100$. All of the locomotor activity, including baseline and morphine-induced locomotor activity, was normalized to the interval that produced the maximum morphine locomotor effect (maximum interval) $(45-60 \mathrm{~min})$ in the saline-pretreated group. The formula is as follows: (number of crossovers per $15 \mathrm{~min} /$ number of crossovers at maximum interval) $\times 100$. Each experimental group was normalized to the corresponding saline-pretreated group. For analgesic tolerance and locomotor sensitization, we used two-way repeated-measures ANOVA (SuperANOVA).

In analyzing morphine-induced MAPK modulation, staining in each 
brain area in the experimental group was normalized to the corresponding staining in the saline control group. The change in staining compared with saline controls was calculated using the following formula: [(experimental value/saline control average $) \times 100]-100$. Statistical analysis was conducted using one-way ANOVA and Tukey's post hoc comparisons.

\section{Results}

Acute morphine administration modulates MAPK activation in the brain

After $6 \mathrm{~d}$ of habituation to the injection procedure, modulation of MAPK activation was observed $30 \mathrm{~min}$ after 10 or $100 \mathrm{mg} / \mathrm{kg}$ morphine administration. We initially stained sections through the entire brain and looked for modulation in phospho-MAPK immunostaining. Surprisingly, modulation was not observed in many areas rich in opioid receptors, such as the habenular, periaqueductal gray (PAG), raphe magnus, and VTA. In areas in which we observed modulation, changes in phospho-MAPK staining were semiquantified, as described in Materials and Methods. After $10 \mathrm{mg} / \mathrm{kg}$ morphine, a significant increase in activation of MAPK was observed in the anterior cingulate (Acc) (Figs. 1A, 2A), somatosensory cortex (Figs. $1 B, 2 B$ ), association cortex (Figs. $1 C, 2 C$ ), as well as the LC (Figs. $1 D, 2 D$ ). In the LC, but not in the cortical regions, there was a significant increase in activation between 10 and $100 \mathrm{mg} / \mathrm{kg}$ (Fig. 2D). The posterior basolateral amygdala (BLA) was less sensitive to morphine and showed significant MAPK activation only after $100 \mathrm{mg} / \mathrm{kg}(p<$ 0.05 ) (Fig. $2 G$ ). In contrast, a significant decrease in MAPK activation was observed after $10 \mathrm{mg} / \mathrm{kg}$ in the nucleus accumbens (NAc) (Figs. $1 E, 2 E$ ) and central amygdala (CeA) (Figs. $1 F, 2 F$ ), with no additional decrease between 10 and $100 \mathrm{mg} / \mathrm{kg}$ morphine. In CA3 of the hippocampus, there was no acute effect of morphine on MAPK activation (Fig. $2 H$ ).

\section{Morphine-induced MAPK activation is completely localized in cells that contain $\mu$-opioid receptors in LC, but not in the cortex}

Confocal analysis revealed $\mu$ receptor staining on both cell bodies and processes with the anticipated cellular membrane-like distribution. Phospho-MAPK staining appeared primarily cytosolic and was observed in large cell bodies with processes. Double-label immunohistochemistry indicated that, in the cortical areas, the majority of morphine-induced MAPK activation did not occur in cells expressing the $\mu$-opioid receptor (Fig. $3 A-C$ ). In contrast, MAPK activation colocalized with the $\mu$ receptor in the LC (Fig. $3 D$ ).

\section{Dependency of morphine-induced MAPK modulation on NMDA receptor activation}

The NMDA receptor antagonist CPP (30 mg/kg, i.p.), when given simultaneously with morphine $(10 \mathrm{mg} / \mathrm{kg}$, s.c.), blocked morphine-induced MAPK modulation in some, but not all, of the brain areas (Fig. 4). In the Acc and the somatosensory cortex, there was a large reduction in baseline phospho-MAPK staining after CPP and a complete blockade of morphine-induced MAPK activation (Fig. $4 A, B$ ). In the association cortex, there was also a reduction in baseline phospho-MAPK staining, but the effect of morphine was retained (Fig. 4C). In the LC, a significant elevation of baseline MAPK activation was observed after NMDA receptor blockade, and morphine-induced MAPK activation was unaltered (Fig. 4D). The morphine-induced decrease in MAPK activation in both the NAc and CeA was unaltered with CPP, and there were no associated baseline changes (Fig. $4 E, F$ ).
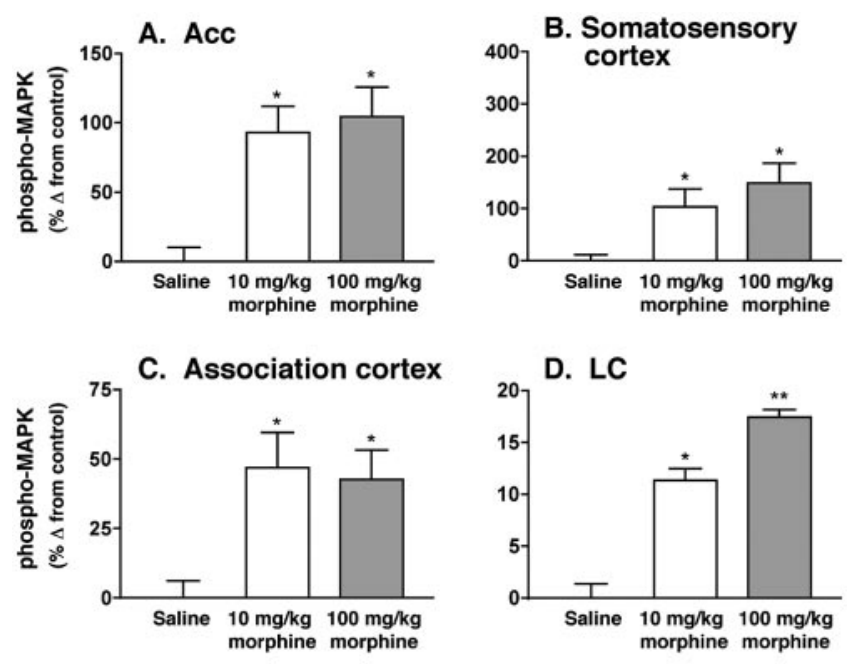

D. LC

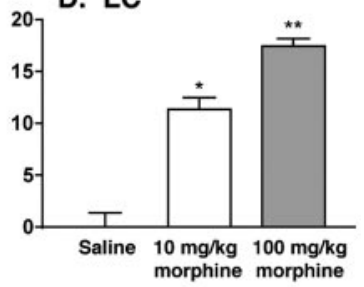

E. NAc

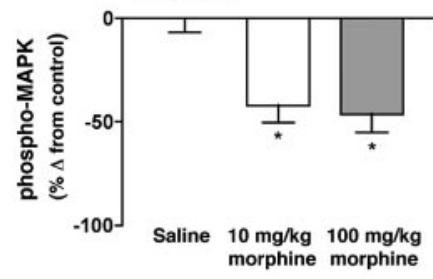

F. CeA
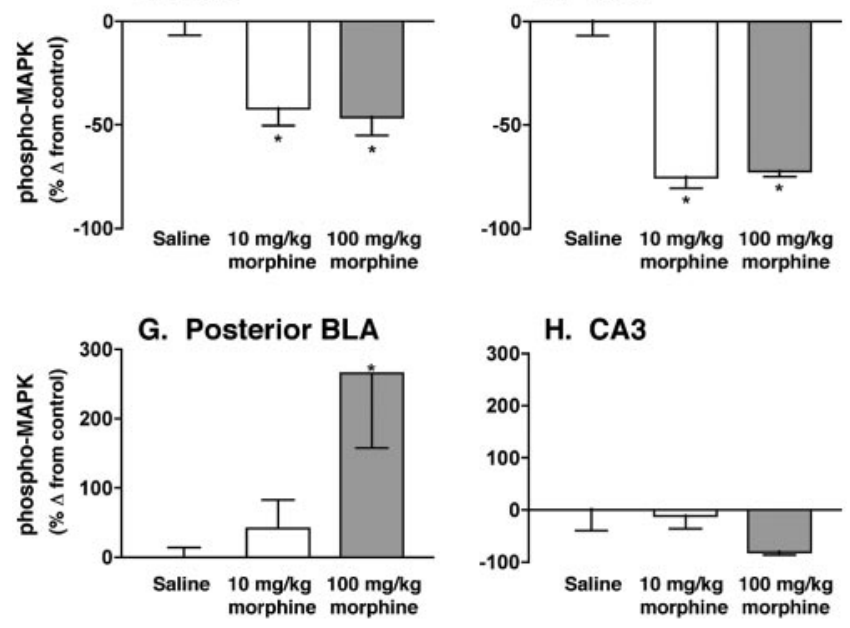

H. CA3

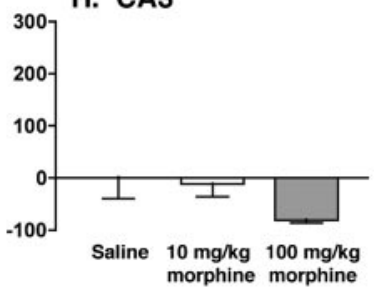

Figure 2. Acute morphine-induced MAPK modulation. Mice were habituated and then injected with saline, $10 \mathrm{mg} / \mathrm{kg}$ morphine, or $100 \mathrm{mg} / \mathrm{kg}$ morphine (subcutaneous). Thirty minutes after injection, mice were perfused, and brains were processed for immunohistochemistry. Digital images were quantified using $\mathrm{NIH} \mathrm{Image.} \mathrm{Results} \mathrm{are} \mathrm{presented} \mathrm{from} \mathrm{5-12} \mathrm{mice} \mathrm{per} \mathrm{treatment} \mathrm{group,} \mathrm{and} \mathrm{for} \mathrm{each}$ brain area, at least five consecutive sections were analyzed. One-way ANOVA revealed a main effect of morphine for the Acc (total pixels stained, $F_{(2,26)}=11.72 ; p<0.001$ ), somatosensory cortex (total pixels stained, $\left.F_{(2,18)}=5.02 ; p<0.05\right)$, association cortex (total pixels stained, $F_{(2,9)}=6.42 ; p<$ $0.05)$, LC (average optical density, $\left.F_{(2,17)}=44.80 ; p<0.0001\right), \mathrm{NAc}$ (total pixels stained, $F_{(2,26)}=$ $11.07 ; p<0.001$ ), CeA (total pixels stained, $F_{(2,26)}=54.39 ; p<0.0001$ ), and posterior BLA (total pixels stained, $\left.F_{(2,26)}=6.42 ; p<0.01\right)$. There was no main effect of morphine in the hippocampus (total pixels stained, $\left.F_{(2,26)}=1.47 ; p>0.05\right)$ ). Tukey's post hoc comparisons revealed a significant increase after 10 and $100 \mathrm{mg} / \mathrm{kg}$ morphine in the $A c c(A)$, somatosensory cortex $(B)$, association cortex $(C$, and $L C(D)$. In the posterior BLA, a significant increase was observed only after $100 \mathrm{mg} / \mathrm{kg}$ (G). A significant decrease in MAPK activation after morphine treatment was observed in the $\mathrm{NAc}(E)$ and CeA ( $F$. No significant difference was observed in CA3 of the hippocampus $(H)$. * Significant difference from saline $(p<0.05)$. * Significant difference from $10 \mathrm{mg} / \mathrm{kg}$ morphine $(p<0.05)$. Results are presented as mean \pm SEM.

\section{Dissociation of analgesic tolerance and locomotor} sensitization after different morphine regimens (TAD vs EOD)

It has been reported previously that injection intervals of at least 24 $\mathrm{hr}$ are required to produce locomotor sensitization to morphine in mice (Kuribara, 1996). We therefore reasoned that shorter intervals using escalating doses would produce robust analgesic tolerance and eliminate the expression of locomotor sensitization, whereas longer intervals (48 hr) would maximize locomotor sensitization. We established two drug regimens, TAD and EOD, in which the animals 


\section{Mu receptor}

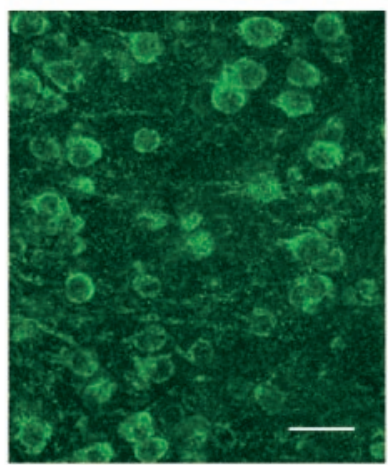

B.

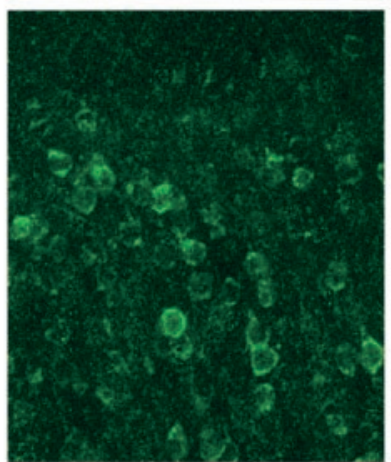

C.

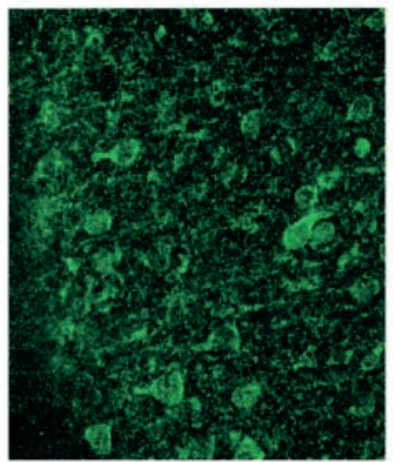

D.

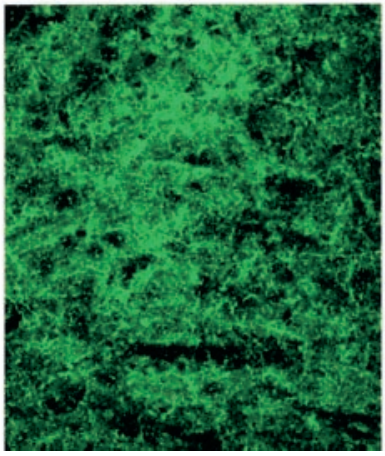

Phospho-MAPK
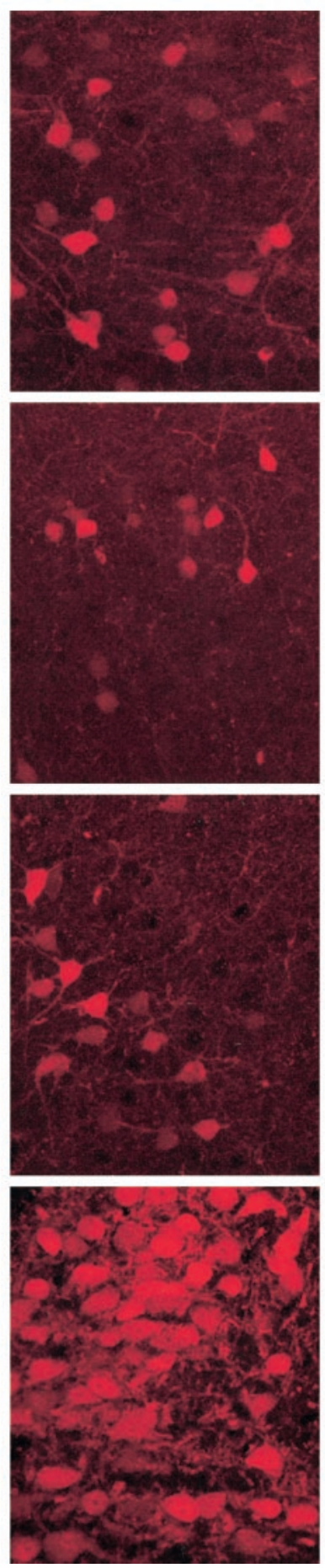

\section{$\mathrm{Mu} /$ phospho-MAPK}
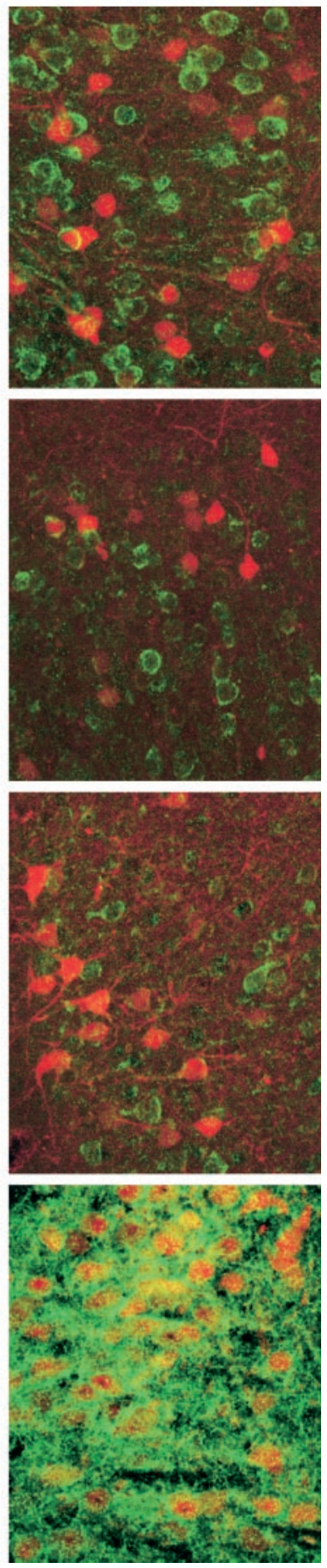

Figure 3. Morphine-induced MAPK activation is predominantly not localized in cells expressing the $\mu$-opioid receptor, except in the LC. Mice were habituated to injections for $6 \mathrm{~d}$ and, on day 7 , were injected with $10 \mathrm{mg} / \mathrm{kg}$ morphine (subcutaneous). Thirty minutes after injection, mice were perfused, and brains were processed for double-labeled immunohistochemistry. Confocal analysis revealed that, in the Acc $(A)$, somatosensory cortex $(B)$, and association cortex $(C)$, the majority of morphine-induced MAPK activation occurred in cells not expressing the $\mu$-opioid receptor. However, there was complete localization of MAPK activation with the $\mu$ receptor in the LC (D). Scale bar, $30 \mu \mathrm{m}$.

demonstrated exclusively analgesic tolerance or locomotor sensitization, respectively, at the time of assessment.

\section{Analgesic tolerance}

After TAD and EOD administration, mice were tested for analgesia using $10 \mathrm{mg} / \mathrm{kg}$ morphine (subcutaneous), which produced $\sim 75 \%$ MPE in control mice (Fig. $5 A$ ). With respect to TAD administration, two-way repeated-measures ANOVA indicated that significant analgesic tolerance developed ( $p=0.001$ ). In contrast, after EOD administration, no significant tolerance developed $(p>0.05)$.

\section{Locomotor sensitization}

After TAD and EOD administration, mice were tested for locomotor activity after $5 \mathrm{mg} / \mathrm{kg}$ morphine (subcutaneous), a dose 

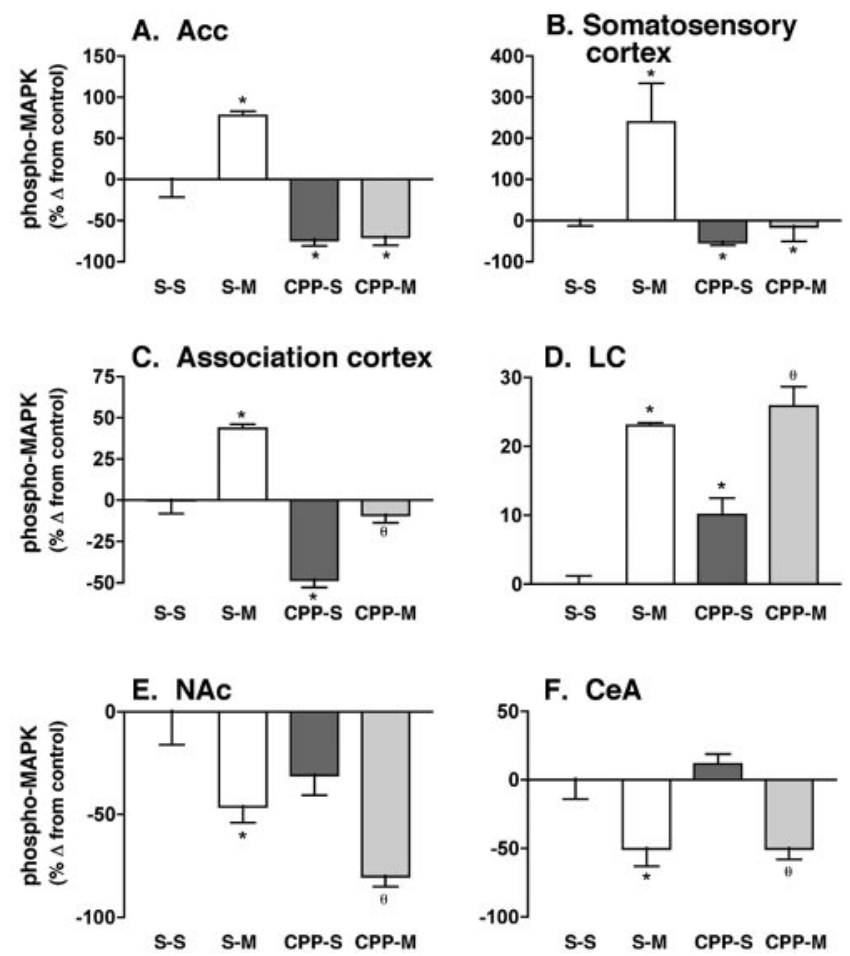

Figure 4. Brain region-specific NMDA receptor blockade of acute morphine-induced MAPK modulation. Mice were habituated and then injected intraperitoneally with saline or CPP, followed immediately by subcutaneous injection of saline or $10 \mathrm{mg} / \mathrm{kg}$ morphine. Thirty minutes later, mice were perfused, brains were processed for immunohistochemistry, and images were analyzed. Results are presented from four to eight mice per treatment group. One-way ANOVA revealed a main effect of morphine for the Acc (total pixels stained, $F_{(3,14)}=25.10 ; p<0.0001$ ), somatosensory cortex (total pixels stained, $F_{(3,14)}=8.09 ; p<0.05$ ), association cortex (total pixels stained, $F_{(3,10)}=17.76 ; p<$ 0.001 ), LC (average optical density, $\left.F_{(3,12)}=37.22 ; p<0.0001\right)$, NAc (total pixels stained, $F_{(3,25)}=$ $9.52 ; p<0.001$ ), and CeA (total pixels stained, $\left.F_{(3,11)}=8.42 ; p<0.05\right)$. S-S, Saline (intraperitoneal) followed by saline (subcutaneous); $S-M$, saline (intraperitoneal) followed by morphine $(10 \mathrm{mg} / \mathrm{kg}$, s.c.); (PP-S, CPP (30 mg/kg, i.p.) followed by saline (subcutaneous); CPP-M, CPP (30 mg/kg, i.p.) followed by $10 \mathrm{mg} / \mathrm{kg}$ morphine. ${ }^{*}$ Significant difference from $S-S(p<0.05)$. ${ }^{\theta}$ Significant difference from CPP-S $(p<0.05)$. Results are presented as mean \pm SEM.

that produces submaximal locomotor stimulation in drug-naive mice (Fig. 5B). Significant sensitization developed to the locomotor-stimulating effect of morphine after EOD administration $(p<0.05)$. In contrast, morphine-induced locomotor stimulation was significantly attenuated after TAD administration $(p=0.0001)$.

In summary, TAD administration produces analgesic tolerance and attenuated morphine-induced locomotion, whereas EOD administration does not produce significant analgesic tolerance but does produce marked sensitization to locomotor activity. Thus, TAD and EOD administration dissociate expression of tolerance and sensitization, which allows comparison of changes in morphine-induced MAPK modulation that are specifically associated with each behavior.

\section{Tolerance to morphine-induced MAPK modulation after} TAD administration

There was no change in baseline MAPK activation after either TAD or EOD administration. TAD administration resulted in complete tolerance to morphine-induced MAPK activation (10 $\mathrm{mg} / \mathrm{kg}$ ) in both the Acc and LC (S-M $>$ TAD-M; $p<0.001$ ) (Fig. $6 A, B)$. In the NAc, partial tolerance developed to the morphineinduced reduction in MAPK phosphorylation (Fig. 6C).

After EOD administration, partial tolerance to morphine-
TAD

EOD

\section{A. Analgesia}
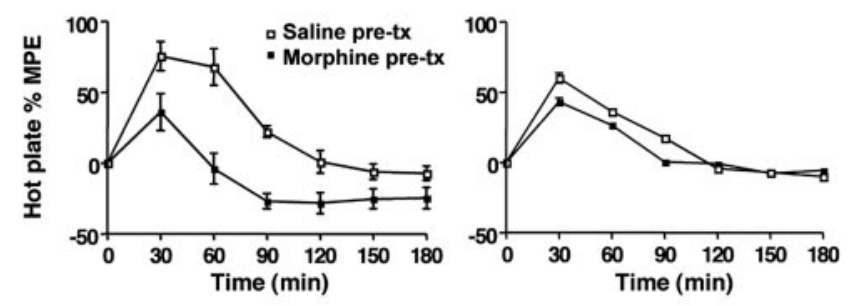

B. Locomotion
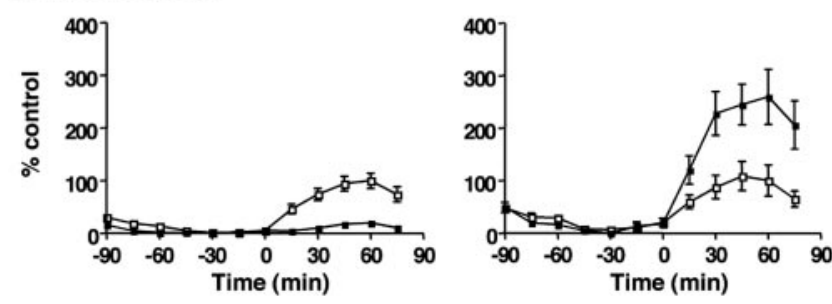

Figure 5. Dissociation of analgesic tolerance and locomotor sensitization after TAD or EOD morphine regimens. Morphine was administered according to TAD or EOD protocols as detailed in Materials and Methods. On day 7, analgesia was measured after $10 \mathrm{mg} / \mathrm{kg}$ morphine $(A)$, or locomotor activity was recorded after $5 \mathrm{mg} / \mathrm{kg}$ morphine $(B)$. Results were analyzed using two-way repeated-measures ANOVA. $A$, Significant analgesic tolerance developed in TAD pretreated mice ( $p=0.001)$. Analysis revealed a significant effect of pretreatment $\left(F_{(1,13)}=\right.$ $16.96 ; p=0.001)$ and time $\left(F_{(1,5)}=44.04 ; p=0.0001\right)$, and an interaction of pretreatment and time $\left(F_{(1,5)}=5.10 ; p<0.001\right)$. In contrast, no significant tolerance developed after EOD administration $(p>0.05)$. Analysis revealed no main effect of pretreatment $\left(F_{(1,14)}=2.30\right.$; $p>0.05)$. Although there was a main effect of time $\left(F_{(1.5)}=48.02 ; p=0.0001\right)$, there was no interaction of pretreatment and time $\left(F_{(1,5)}=1.95 ; p>0.05\right) . B$, Locomotor sensitization developed after EOD administration $(p<0.05)$. Analysis revealed a main effect of pretreatment $\left(F_{(1,10)}=8.59 ; p<0.05\right)$ and time $\left(F_{(1,6)}=8.00 ; p=0.0001\right)$. In contrast, tolerance to the locomotor-stimulating effect of morphine was observed after TAD administration ( $p=$ $0.0001)$. Analysis revealed a main effect of pretreatment $\left(F_{(1,14)}=29.90 ; p=0.0001\right)$ and time $\left(F_{(1,6)}=10.91 ; p=0.0001\right)$. pre-tx, Pretreatment. Results are presented as mean \pm SEM.

induced MAPK activation developed in the LC (S-M > EOD-M; $p<0.05$ ) (see Fig. $8 B$ ). No significant MAPK activation was observed in the Acc after $5 \mathrm{mg} / \mathrm{kg}$ morphine, preventing the assessment of tolerance after EOD administration $(p>0.05)$ (see Fig. 8A).

In summary, the TAD protocol, which produces robust analgesic tolerance, produces significant tolerance to morphineinduced MAPK modulation in the Acc, Nac, and LC.

Lack of tolerance to the morphine-induced decrease in MAPK activation in the CeA after TAD administration

In contrast to the tolerance observed in the Acc, NAc, and LC, morphine retained the same ability to reduce MAPK activation in the CeA after TAD administration $(p>0.05)$ (Fig. 6D). Similarly, the morphine-induced reduction in MAPK activation did not change after EOD administration $(p>0.05)$ (see Fig. $8 C$ ). No significant alteration in baseline MAPK activation was observed in the CeA after TAD or EOD administration $(p>0.05)$.

Instatement of morphine-induced MAPK activation in CA3 of the hippocampus after TAD administration

After acute morphine administration (10 or $100 \mathrm{mg} / \mathrm{kg}$ ), no change in MAPK activation was observed in CA3 of the hippocampus (Fig. $2 H$ ). However, mice that received a morphine challenge after TAD administration exhibited a pronounced instatement in phospho-MAPK staining (Fig. $6 F$ ). This induction 

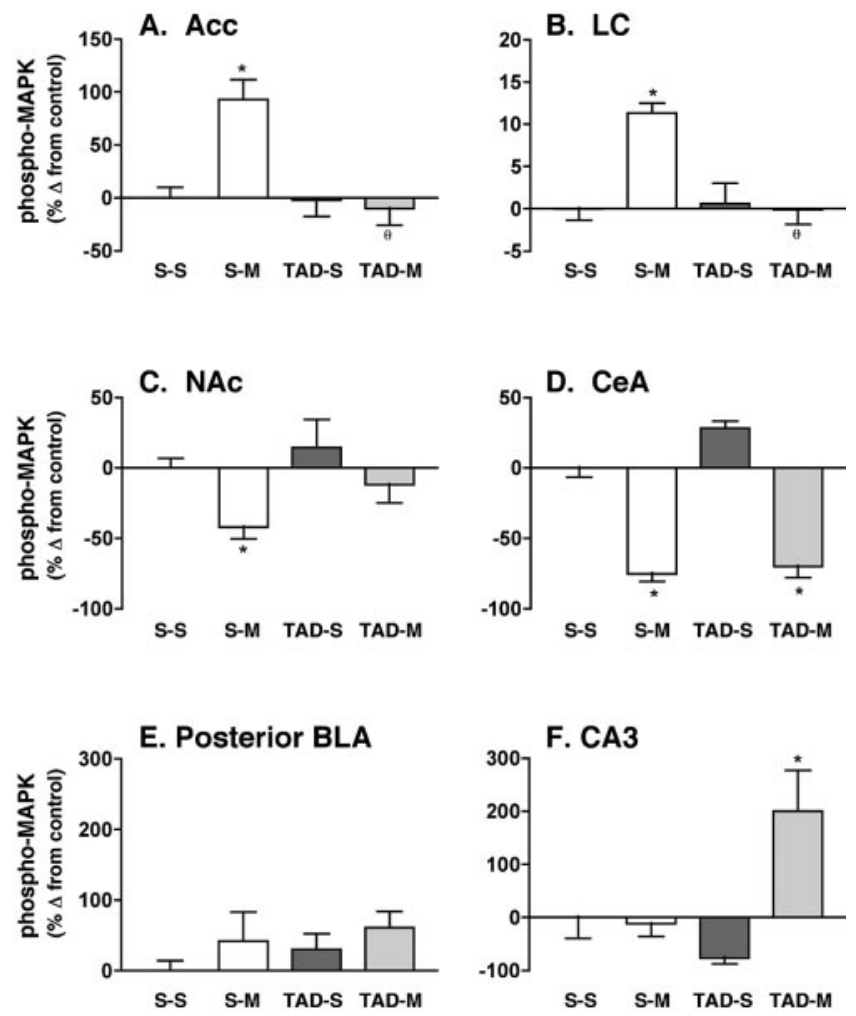

Figure 6. Morphine-induced MAPK modulation after TAD administration. Mice were injected according to the TAD protocol, and on day 7, mice were injected with either saline or 10 $\mathrm{mg} / \mathrm{kg}$ morphine. Results are presented from 5-12 mice per treatment group. One-way ANOVA revealed a main effect of treatment in the $\operatorname{Acc}\left(F_{(3,30)}=10.38 ; p<0.0001\right), \operatorname{NAc}\left(F_{(3,29)}=\right.$ 5.63; $p<0.01)$, $\mathrm{LC}\left(F_{(3,20)}=15.9 ; p<0.0001\right)$, CeA (total pixels stained, $F_{(3,31)}=10.38 ; p<$ 0.0001 ), and $C A 3$ of the hippocampus (total pixels stained, $F_{(3,31)}=6.07 ; p<0.01$ ), and no main effect of treatment in the posterior BLA (total pixels stained, $F_{(3,31)}=0.68 ; p>0.05$ ). Tukey's post hoc comparisons indicated complete tolerance to morphine-induced MAPK activation in the $A c c(A)$ and $L C(B)$ and partial tolerance in the NAC $(O)$. However, no tolerance developed in the CeA $(D)$. No effect was observed in the posterior BLA (E). A striking instatement of morphine-induced MAPK activation was observed in CA3 of the hippocampus ( $F$. S-S, Saline pretreatment followed by saline on test day; $S-M$, saline pretreatment followed by acute morphine $(10 \mathrm{mg} / \mathrm{kg})$ treatment; TAD-S, TAD pretreatment followed by saline treatment; TAD-M, TAD pretreatment followed by $10 \mathrm{mg} / \mathrm{kg}$ morphine. * Significant difference from S-S $(p<0.05)$. ${ }^{\theta}$ Significantdifference from S-M $(p<0.05)$. Results are presented as mean \pm SEM.

of MAPK activation in CA3 was significantly different from both saline-treated mice and mice acutely treated with morphine $(p<$ $0.05)$. The increase in immunolabeling was found exclusively in the processes and was accompanied by a reduction in CA3 cell body staining (Fig. 7). No significant change in baseline MAPK activation was observed in CA3 after TAD administration (Fig. $6 F)(\mathrm{S}-\mathrm{S}=\mathrm{TAD}-\mathrm{S} ; p>0.05)$. A similar trend was observed in EOD-treated mice but did not reach significance (data not shown).

\section{Sensitization to MAPK activation in the posterior BLA after EOD but not TAD administration}

Acute administration of $100 \mathrm{mg} / \mathrm{kg}$ morphine, but not 5 or 10 $\mathrm{mg} / \mathrm{kg}$, caused a significant increase in MAPK activation in the BLA (Fig. $2 G$ ). After EOD administration, $5 \mathrm{mg} / \mathrm{kg}$ morphine produced marked MAPK activation $(p<0.01)$ (Figs. $8 D$, 9). In contrast, TAD administration did not induce any change in BLA MAPK activation in response to a $10 \mathrm{mg} / \mathrm{kg}$ morphine challenge (Fig. 6E). No significant change in baseline MAPK activation was observed after EOD or TAD administration in the BLA. Thus, sensitization to morphine-induced MAPK activation occurred after EOD, but not TAD administration.

\section{Discussion}

The results demonstrate that MAPK is activated after acute systemic morphine administration in many cortical areas and the LC, whereas activation is suppressed in limbic areas such as NAc and CeA. Changes in total MAPK protein levels are unlikely after $30 \mathrm{~min}$, and previous studies found no change in total MAPK protein levels even after repeated morphine administration (Berhow et al., 1996; Schulz and Hollt, 1998). Interestingly, MAPK modulation was not observed in many brain areas rich in opioid receptors including the PAG, raphe magnum, and VTA. Furthermore, except for the LC, MAPK activation was predominantly undetected in cells expressing $\mu$-opioid receptors. One plausible explanation is that competing intracellular signaling pathways suppress MAPK activation. Akt is activated by the $\mu$ receptor in vitro (Polakiewicz et al., 1998b), and activation of the Akt pathway inhibits MAPK signaling (Zimmermann and Moelling, 1999). Alternative explanations include technical limitations of phospho-MAPK detection, temporal differences in activation, or the possibility that opioid receptors do not couple to MAPK in some cells.

Given this lack of colocalization, we questioned whether the modulation was occurring through a different neurotransmitter system. Because it is well established that NMDA receptor antagonists block the development of morphine tolerance and that both NMDA receptors and MAPK are involved in synaptic plasticity, we used the competitive NMDA receptor antagonist CPP to determine whether glutamate transmission plays a role in morphine-induced MAPK modulation. We found that NMDA receptor activation was critical for both baseline and morphineinduced MAPK activation in the Acc and somatosensory cortex. In contrast, although baseline MAPK activation was perturbed in the LC and association cortex, morphine-induced MAPK activation was unaffected by CPP. In the NAc and CeA, there was no effect of CPP on either baseline or the morphine-induced decrease in MAPK activation. In summary, we observed regionspecific NMDA receptor-dependent and -independent mechanisms of acute morphine-induced MAPK modulation.

Most studies indicate that systemic administration of NMDA receptor antagonists either has no effect or increases acute systemic morphine analgesia (Carlezon et al., 2000). Therefore, it is unlikely that the NMDA receptor-dependent MAPK activation we observed in the cortical regions is involved in morphine analgesia. However, previous experiments have shown that NMDA receptors are necessary for the development of morphine tolerance (Trujillo, 2000). This suggests that the NMDA receptordependent activation in cortical areas may represent induction of long-term plasticity that contributes to tolerance. A possible contribution of specific cortical areas to NMDA receptor-mediated attenuation of morphine tolerance has yet to be investigated.

In the NAc, a key structure of the mesolimbic reward pathway, acute morphine administration produced an NMDA receptorindependent decrease in MAPK activation. This decrease has also been reported in rats using Western blot. This may reflect the inhibition of GABAergic interneurons, which could lead to an increase in the excitability of dopaminergic neurons. In contrast to morphine, acute, systemic $\Delta$ 9-tetrahydrocannabinol (THC) results in an increase in MAPK activation in the NAc (Valjent et al., 2001). Although administration of either drug results in adaptations indicative of reward (e.g., place preference), unlike 
A. S-S
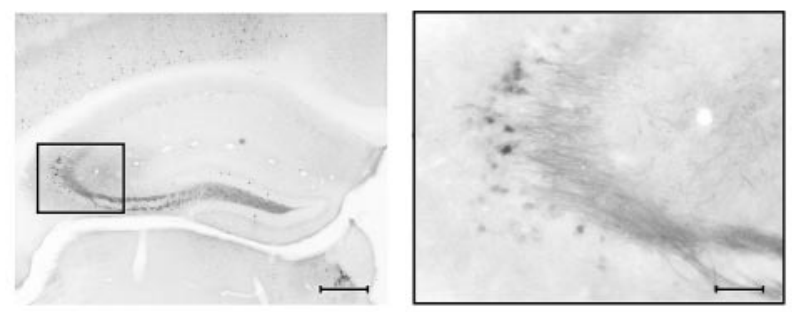

C. TAD-S

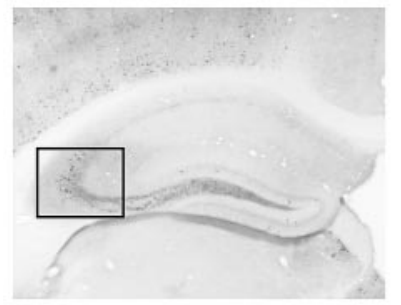

B. S-M
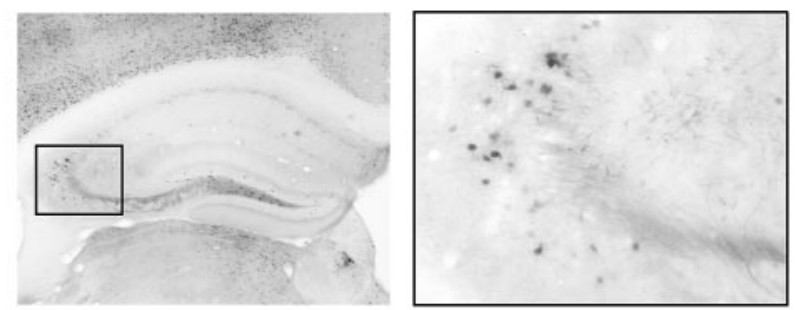

D. TAD-M
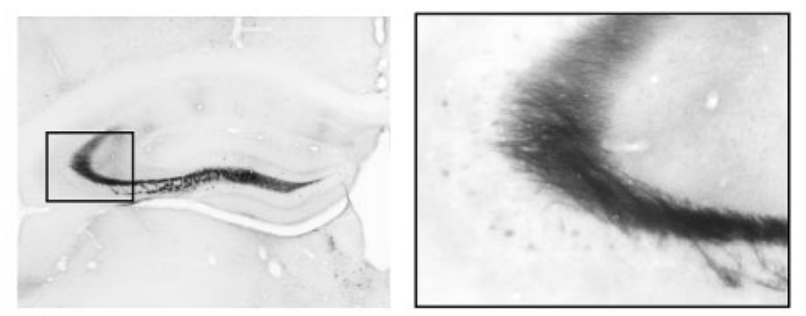

Figure 7. Instatement of morphine-induced MAPK activation in CA3 processes of the hippocampus after TAD administration. Mice were injected according to the TAD protocol and, on day 7, were injected with either saline or $10 \mathrm{mg} / \mathrm{kg}$ morphine. Morphine-induced MAPK activation was not observed in CA3 of control mice $(S-S)(A)$ or mice acutely treated with morphine (10 mg/kg) $(S-M)(B)$. TAD pretreatment produced a dramatic instatement of MAPK activation in processes after morphine (10 mg/kg) (TAD-M) (D) but not saline (TAD-S) (C). There was no change in baseline MAPK activation after TAD pretreatment (S-S vs TAD-S). Representative photographs of CA3 of the hippocampus are shown. The frame inside the photograph on each left panel indicates the magnified area in the photograph on the right. Scale bars: left photographs, $300 \mu \mathrm{m}$; right photographs, $60 \mu \mathrm{m}$.
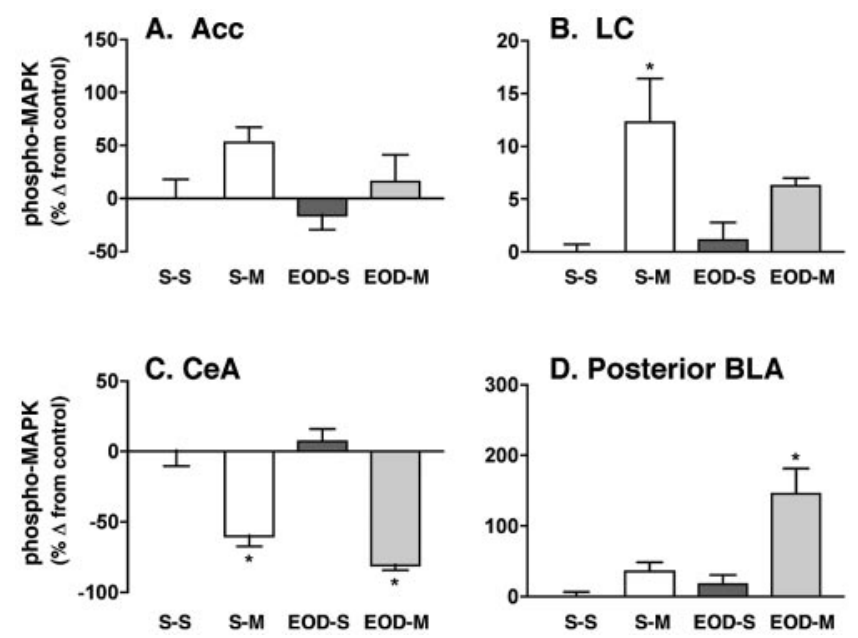

Figure 8. Morphine-induced MAPK modulation after EOD administration. Mice were injected according to the EOD protocol, and on day 7 , mice were injected with $5 \mathrm{mg} / \mathrm{kg}$ morphine. Results are presented from 5-12 mice per treatment group. There was a trend for morphineinduced MAPK activation in the Acc in both S-M and EOD-M $(A)$, although there was no main effect of treatment $\left(F_{(3,18)}=2.39 ; p>0.05\right)$. One-way ANOVA revealed a main effect of treatment in the $\mathrm{LC}\left(F_{(3,12)}=6.04 ; p<0.01\right)$, CeA (total pixels stained, $F_{(3,22)}=33.04 ; p<$ 0.0001 ), and the posterior BLA (total pixels stained, $\left.F_{(3,21)}=8.83 ; p<0.001\right)$. Tukey's post hoc comparisons indicate partial tolerance in the $L C(B)$ and no tolerance in the $C e A(C)$. Significant sensitization developed to morphine-induced MAPK activation in the posterior BLA (D). S-S, Saline pretreatment followed by saline on test day; $S-M$, saline pretreatment followed by acute morphine $(10 \mathrm{mg} / \mathrm{kg})$ treatment; EOD-S, EOD pretreatment followed by saline treatment; EOD-M, EOD pretreatmentfollowed by $5 \mathrm{mg} / \mathrm{kg}$ morphine. * Significant difference from S-S $(p<0.05)$. Results are presented as mean \pm SEM.

morphine, the effect of THC in mice is initially dysphoric, and the demonstration of reward requires careful experimental manipulations (Valjent and Maldonado, 2000). Thus, the disparate signaling observed between morphine and THC in the NAc may reflect the differences between opiate and cannabinoid reward.
Because we found brain areas of MAPK modulation related to analgesia and reward in response to acute morphine, we next looked for biochemical correlates of MAPK activation with adaptive behaviors. For this purpose, we developed protocols that isolate the expression of either morphine analgesic tolerance (TAD) or locomotor sensitization (EOD) at the time of assessment of MAPK modulation. After TAD, but not EOD, administration, complete tolerance to morphine-induced MAPK activation was observed in the Acc and LC, areas of pain processing that exhibited NMDA receptor-dependent and -independent MAPK activation. No changes in baseline MAPK activation were observed in any of the brain areas examined after TAD administration, suggesting that the tolerance observed is a specific decrement in morphine-induced signaling. The adaptation in MAPK signaling is probably not attributable to $\mu$-opioid receptor desensitization, because stimulated GTP $\gamma \mathrm{S}$ binding after chronic morphine has been shown to be unperturbed in areas other than the brainstem (Sim-Selley et al., 2000).

In the amygdala, the CeA showed an NMDA receptorindependent decrease in MAPK activation after acute morphine and was the only area examined that did not show tolerance to morphine-induced MAPK modulation. The CeA contributes to morphine analgesia (Pavlovic et al., 1996), reward (Rezayof et al., 2002), and conditioned opioid analgesia (Watkins et al., 1993). Thus, this structure may be an important target for producing opiate analgesia without triggering tolerance.

Locomotor sensitization is a model for drug relapse and craving and, for opiates, is thought to be caused by an inhibition of GABAergic interneurons in the VTA that disinhibit dopaminergic neurons, thus leading to dopamine release in the NAc (for review, see Vanderschuren and Kalivas, 2000). Lesion experiments have established the importance of the amygdala for sensitization to drugs of abuse (Squillace et al., 1982; Kalivas and Alesdatter, 1993). This area may contribute to sensitization through the convergence of extensive sensory input of environ- 
A. S-S

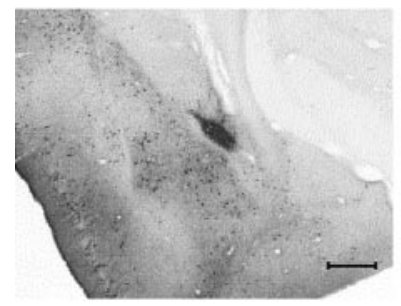

B. S-M

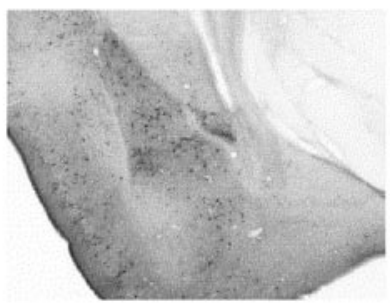

C. EOD-S

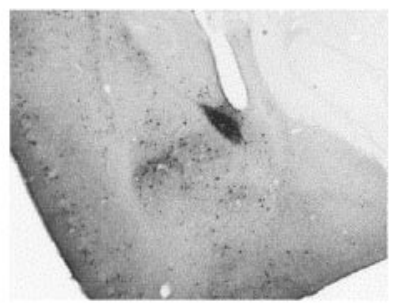

\section{EOD-M}

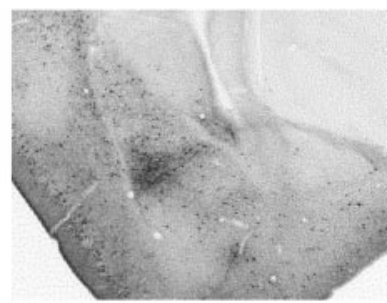

Figure 9. Sensitization to MAPK activation in the posterior BLA after EOD administration. Mice were injected according to the EOD protocol, and on day 7 , mice were injected with 5 mg/kg morphine. Morphine-induced MAPK activation was not observed in control mice (S-S) ( $A$ ) or those acutely treated with $5 \mathrm{mg} / \mathrm{kg}$ morphine (S-M) (B). There was no change in baseline MAPK activation after EOD pretreatment (EOD-S) (C). Sensitization to morphine-induced MAPK activation was observed in mice receiving EOD pretreatment followed by $5 \mathrm{mg} / \mathrm{kg}$ morphine treatment (EOD-M) (D). Photographs are representative DAB-stained sections. Scale bar, $300 \mu \mathrm{m}$.

mental cues from reciprocal connections with sensory neocortex (e.g., somatosensory and auditory cortices) and frontal lobe (e.g., Acc, insular cortex, and orbitofrontal cortex). One result that distinguishes different patterns of MAPK modulation during sensitization and tolerance was the marked potentiation of morphine-induced MAPK activation in the BLA after EOD, but not TAD, administration. A previous study found a correlation between locomotor sensitization and morphine-induced increases in SPARC (secreted protein acidic rich in cysteine) in the BLA (Ikemoto et al., 2000). Together, these results provide correlative evidence that plasticity in the BLA contributes specifically to locomotor sensitization.

The increased MAPK activation in the posterior BLA represents a selective, sensitized signaling response to morphine that parallels the locomotor sensitization, but not analgesic tolerance. This could reflect an increase in excitatory transmission in the NAc that contributes to this behavior, because excitatory projections from the BLA synapse on dopaminergic neurons of the NAc (Johnson et al., 1994). Recent work shows that tetanic stimulation of the BLA results in potentiation of evoked firing in the NAc (Floresco et al., 2001). Moreover, high-frequency stimulation of the BLA, but not the CeA, produces a long-lasting glutamate receptor-dependent increase in dopamine efflux into the NAc (Floresco et al., 1998; Howland et al., 2002). Together, this suggests that the effect of morphine on the BLA may contribute to locomotor sensitization via influencing dopamine release in the NAc.

Another striking result was the instatement of morphineinduced MAPK activation in CA3 processes of the hippocampus after TAD administration. This instatement could be explained either by modulation of opioid receptor mediated coupling directly to the MAPK pathway, or more likely, by activitydependent synaptic plasticity. Future experiments will determine the cell types containing the phospho-MAPK-stained processes, the types of processes, and whether this potentiated response to morphine in CA3 is dependent on NMDA receptor signaling.

Adaptive behaviors such as analgesic tolerance are known to have a learned component in which the context of administration becomes associated with the effects of the drug and thus contributes to the adaptation (Siegel, 1975). Because of the role of the hippocampus in associative learning, the results observed in CA3 may be attributable to learning or memory processes that are instated by the context and/or the onset of drug administration. Mice lacking the NR1 subunit of the NMDA receptor in CA3 exhibit normal spatial memory when cues are fully presented in the Morris water maze but are unable to demonstrate pattern completion when only a fraction of the cues are presented $(\mathrm{Na}-$ kazawa et al., 2002). Thus, the instatement of morphine-induced
MAPK activation after repeated administration may represent the integration of contextual cues with interoceptive cues from the onset of the drug. Future experiments that differentiate associative and nonassociative adaptive behaviors will determine whether the effect in CA3 is dependent on the context of morphine administration.

Although opiates are commonly used for treating pain, the mechanisms underlying adaptive processes (e.g., tolerance, abuse, withdrawal, and relapse) remain somewhat elusive. The purpose of this study was to identify brain pathways and signaling cascades involved in both the acute and chronic actions of morphine. We focused on the MAPK pathway and NMDA receptors, because both play important roles in synaptic plasticity and have been implicated in the chronic adaptations to opiates. This study demonstrates brain region-specific mechanisms regulating MAPK activation after acute morphine administration. Different brain areas showed tolerance, sensitization, instatement, or retention of morphine-induced MAPK modulation after repeated morphine administration. Dissociation of analgesic tolerance and locomotor sensitization enabled the identification of brain circuitry and biochemical changes that may contribute specifically to each behavior. Future studies will examine links between NMDA receptor activation, MAPK signaling, and discrete behavioral adaptations.

\section{References}

Adams JP, Roberson ED, English JD, Selcher JC, Sweatt JD (2000) MAPK regulation of gene expression in the central nervous system. Acta Neurobiol Exp (Warsz) 60:377-394.

Berhow MT, Hiroi N, Nestler EJ (1996) Regulation of ERK (extracellular signal regulated kinase), part of the neurotrophin signal transduction cascade, in the rat mesolimbic dopamine system by chronic exposure to morphine or cocaine. J Neurosci 16:4707-4715.

Carlezon Jr WA, Kosten TA, Nestler EJ (2000) Behavioral interactions caused by combined administration of morphine and MK-801 in rats. Psychopharmacology (Berl) 151:261-272.

Eisinger DA, Ammer H, Schulz R (2002) Chronic morphine treatment inhibits opioid receptor desensitization and internalization. J Neurosci 22:10192-10200.

Floresco SB, Yang CR, Phillips AG, Blaha CD (1998) Basolateral amygdala stimulation evokes glutamate receptor-dependent dopamine efflux in the nucleus accumbens of the anaesthetized rat. Eur J Neurosci 10:1241-1251.

Floresco SB, Blaha CD, Yang CR, Phillips AG (2001) Dopamine D1 and NMDA receptors mediate potentiation of basolateral amygdala-evoked firing of nucleus accumbens neurons. J Neurosci 21:6370-6376.

Gutkind JS (2000) Regulation of mitogen-activated protein kinase signaling networks by G protein-coupled receptors. Sci STKE 2000:RE1.

Gutstein HB, Rubie EA, Mansour A, Akil H, Woodgett JR (1997) Opioid 
effects on mitogen-activated protein kinase signaling cascades. Anesthesiology 87:1118-1126.

Harrison JM, Allen RG, Pellegrino MJ, Williams JT, Manzoni OJ (2002) Chronic morphine treatment alters endogenous opioid control of hippocampal mossy fiber synaptic transmission. J Neurophysiol 87:2464-2470.

Howland JG, Taepavarapruk P, Phillips AG (2002) Glutamate receptordependent modulation of dopamine efflux in the nucleus accumbens by basolateral, but not central, nucleus of the amygdala in rats. J Neurosci 22:1137-1145.

Ikemoto M, Takita M, Imamura T, Inoue K (2000) Increased sensitivity to the stimulant effects of morphine conferred by anti-adhesive glycoprotein SPARC in amygdala. Nat Med 6:910-915.

Johnson LR, Aylward RL, Hussain Z, Totterdell S (1994) Input from the amygdala to the rat nucleus accumbens: its relationship with tyrosine hydroxylase immunoreactivity and identified neurons. Neuroscience 61:851-865.

Kalivas PW, Alesdatter JE (1993) Involvement of $N$-methyl-D-aspartate receptor stimulation in the ventral tegmental area and amygdala in behavioral sensitization to cocaine. J Pharmacol Exp Ther 267:486-495.

Kuribara H (1996) Effects of interdose interval on ambulatory sensitization to methamphetamine, cocaine and morphine in mice. Eur J Pharmacol 316:1-5.

Lancellotti D, Unterwald EM (2003) ERK is regulated in the nucleus accumbence by acute, but not repeated morphine administration in rats. College on Problems of Drug Dependence Abstracts 53:91.

Law PY, Wong YH, Loh HH (2000) Molecular mechanisms and regulation of opioid receptor signaling. Annu Rev Pharmacol Toxicol 40:389-430.

Mansouri FA, Motamedi F, Fathollahi Y, Atapour N, Semnanian S (1997) Augmentation of LTP induced by primed-bursts tetanic stimulation in hippocampal CA1 area of morphine dependent rats. Brain Res 769:119-124.

Mansouri FA, Motamedi F, Fathollahi Y (1999) Chronic in vivo morphine administration facilitates primed-bursts-induced long-term potentiation of Schaffer collateral-CAl synapses in hippocampal slices in vitro. Brain Res 815:419-423.

Marek P, Ben-Eliyahu S, Gold M, Liebeskind JC (1991) Excitatory amino acid antagonists (kynurenic acid and MK-801) attenuate the development of morphine tolerance in the rat. Brain Res 547:77-81.

Mazzucchelli C, Vantaggiato C, Ciamei A, Fasano S, Pakhotin P, Krezel W, Welzl H, Wolfer DP, Pages G, Valverde O, Marowsky A, Porrazzo A, Orban PC, Maldonado R, Ehrengruber MU, Cestari V, Lipp HP, Chapman PF, Pouyssegur J, Brambilla R (2002) Knockout of ERK1 MAP kinase enhances synaptic plasticity in the striatum and facilitates striatalmediated learning and memory. Neuron 34:807-820.

Nakazawa K, Quirk MC, Chitwood RA, Watanabe M, Yeckel MF, Sun LD, Kato A, Carr CA, Johnston D, Wilson MA, Tonegawa S (2002) Requirement for hippocampal CA3 NMDA receptors in associative memory recall. Science 297:211-218.

Pavlovic ZW, Cooper ML, Bodnar RJ (1996) Opioid antagonists in the periaqueductal gray inhibit morphine and $\beta$-endorphin analgesia elicited from the amygdala of rats. Brain Res 741:13-26.

Polakiewicz RD, Schieferl SM, Dorner LF, Kansra V, Comb MJ (1998a) A mitogen-activated protein kinase pathway is required for $\mu$-opioid receptor desensitization. J Biol Chem 273:12402-12406.

Polakiewicz RD, Schieferl SM, Gingras AC, Sonenberg N, Comb MJ (1998b) $\mu$-Opioid receptor activates signaling pathways implicated in cell survival and translational control. J Biol Chem 273:23534-23541.

Pu L, Bao GB, Xu NJ, Ma L, Pei G (2002) Hippocampal long-term potenti- ation is reduced by chronic opiate treatment and can be restored by reexposure to opiates. J Neurosci 22:1914-1921.

Rezayof A, Zarrindast MR, Sahraei H, Haeri-Rohani AH (2002) Involvement of dopamine D2 receptors of the central amygdala on the acquisition and expression of morphine-induced place preference in rat. Pharmacol Biochem Behav 74:187-197.

Robinson TE, Berridge KC (1993) The neural basis of drug craving: an incentive-sensitization theory of addiction. Brain Res Brain Res Rev 18:247-291.

Saal D, Dong Y, Bonci A, Malenka RC (2003) Drugs of abuse and stress trigger a common synaptic adaptation in dopamine neurons. Neuron 37:577-582.

Schulz S, Hollt V (1998) Opioid withdrawal activates MAP kinase in locus coeruleus neurons in morphine-dependent rats in vivo. Eur J Neurosci 10:1196-1201.

Siegel S (1975) Evidence from rats that morphine tolerance is a learned response. J Comp Physiol Psychol 89:498-506.

Sim-Selley LJ, Selley DE, Vogt LJ, Childers SR, Martin TJ (2000) Chronic heroin self-administration desensitizes $\mu$-opioid receptor-activated G-proteins in specific regions of rat brain. J Neurosci 20:4555-4562.

Squillace KM, Post RM, Pert A (1982) Effect of lidocaine pretreatment on cocaine-induced behavior in normal and amygdala-lesioned rats. Neuropsychobiology 8:113-122.

Sweatt JD (2001) The neuronal MAP kinase cascade: a biochemical signal integration system subserving synaptic plasticity and memory. J Neurochem 76:1-10.

Thiels E, Kanterewicz BI, Norman ED, Trzaskos JM, Klann E (2002) Longterm depression in the adult hippocampus in vivo involves activation of extracellular signal-regulated kinase and phosphorylation of Elk-1. J Neurosci 22:2054-2062.

Trujillo KA (2000) Are NMDA receptors involved in opiate-induced neural and behavioral plasticity? A review of preclinical studies. Psychopharmacology (Berl) 151:121-141.

Trujillo KA, Akil H (1991) Inhibition of morphine tolerance and dependence by the NMDA receptor antagonist MK-801. Science 251:85-87.

Unterwald EM, Anton B, To T, Lam H, Evans CJ (1998) Quantitative immunolocalization of $\mu$ opioid receptors: regulation by naltrexone. Neuroscience 85:897-905.

Vaillant AR, Zanassi P, Walsh GS, Aumont A, Alonso A, Miller FD (2002) Signaling mechanisms underlying reversible, activity-dependent dendrite formation. Neuron 34:985-998.

Valjent E, Maldonado R (2000) A behavioural model to reveal place preference to $\Delta$ 9-tetrahydrocannabinol in mice. Psychopharmacology (Berl) 147:436-438

Valjent E, Pages C, Rogard M, Besson MJ, Maldonado R, Caboche J (2001) $\Delta 9$-Tetrahydrocannabinol-induced MAPK/ERK and Elk-1 activation in vivo depends on dopaminergic transmission. Eur J Neurosci 14:342-352.

Vanderschuren LJ, Kalivas PW (2000) Alterations in dopaminergic and glutamatergic transmission in the induction and expression of behavioral sensitization: a critical review of preclinical studies. Psychopharmacology (Berl) 151:99-120.

Watkins LR, Wiertelak EP, Maier SF (1993) The amygdala is necessary for the expression of conditioned but not unconditioned analgesia. Behav Neurosci 107:402-405.

Williams JT, Christie MJ, Manzoni O (2001) Cellular and synaptic adaptations mediating opioid dependence. Physiol Rev 81:299-343.

Zimmermann S, Moelling K (1999) Phosphorylation and regulation of Raf by Akt (protein kinase B). Science 286:1741-1744. 